\title{
A teleconsulta e o alcance da assistência na lógica clínica epidemiológica: um relato de experiência
}

\author{
Teleconsultation and The Scope of Care in Epidemiological Clinical Logic: An Experience Report \\ Teleconsulta y el alcance de la atención en la lógica clínica epidemiológica: Un informe de experiência
}

\begin{abstract}
RESUMO
A telemedicina é uma ferramenta recente instituída pelo Ministério da Saúde, que permite a realização de suporte e assistência médica de forma remota/virtual. Objetivo: Avaliar a experiência do uso da telemedicina como mecanismo alternativo para prestação da assistência à saúde de casos suspeitos durante a pandemia de COVID-19. Método: Um estudo epidemiológico observacional descritivo. Realizado análise do prontuário médico em relação aos atendimentos oferecidos pelo Sindicato da categoria aos trabalhadores de dois frigoríficos da região Sul de Santa Catarina, em abril de 2020. Resultados: Houve procura de 40 funcionários, a maioria mulheres (55,3\%), da cidade de Forquilhinha - SC $(76,3 \%)$ e $36,8 \%$ trabalhavam no setor corte de coxa. Os sintomas mais referidos foram tosse e congestão nasal, houve suspeita de Covid-19 em 32 trabalhadores. Conclusão: A telemedicina é uma ferramenta que contribui para a diminuição da disseminação do vírus e proporciona assistência à saúde contemplando um maior número de indivíduos.
\end{abstract}

Descritores: Telemedicina; Teleconsulta; Covid-19.

\section{ABSTRACT}

Telemedicine is a recent tool created by the Ministry of Health, which allows for remote/virtual support and medical assistance. Objective: To evaluate the experience of using telemedicine as an alternative mechanism for providing health care to suspected cases during the COVID-19 pandemic. Method: A descriptive observational epidemiological study. Analysis of the medical record was carried out in relation to the services offered by the union of the category to workers of two slaughterhouses in the southern region of Santa Catarina, in April 2020. Results: There was demand for 40 employees, mostly women (55.3\%), from city of Forquilhinha - SC (76.3\%) and $36.8 \%$ worked in the thigh cutting sector. The most reported symptoms were cough and nasal congestion, with suspicion of Covid-19 in 32 workers. Conclusion: Telemedicine is a tool that contributes to reducing the spread of the virus and provides health care covering a greater number of individuals.

Key Words: Telemedicine; Teleconsultation; Covid-19.

\section{RESUMEN}

La telemedicina es una herramienta reciente creada por el Ministerio de Salud, que permite el apoyo y la asistencia médica remota / virtual. Objetivo: Evaluar la experiencia del uso de la telemedicina como mecanismo alternativo para brindar atención médica a casos sospechosos durante la pandemia de COVID-19. Método: Estudio epidemiológico observacional descriptivo. Se realizó el análisis de la historia clínica en relación a los servicios ofrecidos por el sindicato de la categoría a los trabajadores de dos mataderos de la región sur de Santa Catarina, en abril de 2020. Resultados: Hubo demanda de 40 empleados, en su mayoría mujeres $(55,3 \%)$, de la ciudad de Forquilhinha - SC $(76,3 \%)$ y el $36,8 \%$ trabajaba en el sector de corte de muslos. Los síntomas más reportados fueron tos y congestión nasal, con sospecha de Covid-19 en 32 trabajadores. Conclusión: la telemedicina es una herramienta que contribuye a reducir la propagación del virus y brinda atención médica que cubre a un mayor número de personas.

Palabras clave: Telemedicina; Teleconsulta; Covid-19.

RECEBIMENTO: XX APROVAÇÃO: XX 


\section{artigo}

Matias, M. L., Ruiz, R. C., Justo, T. S., Ribeiro, V. L., Longen, W. C.

A teleconsulta e o alcance da assistência na lógica clínica epidemiológica: um relato de experiência

\section{Marcos Lenon Matias}

Fisioterapeuta. Mestre em Saúde coletiva. Membro do Núcleo de Promoção e Atenção Clínica á Saúde do Trabalhador/NUPAC-ST. Criciúma/SC

ORCID:

\section{Roberto Carlos Ruiz}

Médico do Trabalho. Membro do Núcleo de Promoção e Atenção Clínica á Saúde do Trabalhador/NUPAC-ST. Criciúma/SC. Professor da UFSC- Florianópolis/SC

ORCID:

\section{Taís Sparremberger Justo}

Acadêmica do curso de fisioterapia na Universidade do Extremo Sul Catarinense. Bolsista do Núcleo de Promoção e Atenção Clínica á Saúde do Trabalhador/NUPAC-ST. Criciúma/SC

ORCID:

\section{Vitória Lessa Ribeiro}

Acadêmica do curso de fisioterapia na Universidade do Extremo Sul Catarinense. Bolsista do Núcleo de Promoção e Atenção Clínica á Saúde do Trabalhador/NUPAC-ST. Criciúma/SC

ORCID:

\section{Willians Cassiano Longen}

Fisioterapeuta. Doutor em Ciências da Saúde. Coordenador do NUPAC-ST. Professor do Programa de Pós-Graduação em Saúde Coletiva-PPGSCol. Universidade do Extremo Sul Catarinense - UNESC - Santa Catarina (SC)

ORCID:

\section{INTRODUÇÃO}

Em meio à pandemia, cientistas fazem pesquisa em ritmo acelerado para saber o comportamento do vírus, a fisiopatologia da doença, as medidas preventivas, tratamento ou o modo de organização dos serviços de saúde para fazer frente ao momento atual que vivemos. O que fazer? Essa pergunta é uma das mais frequentes feitas em todo o mundo no momento.

A pandemia atual causada pelo vírus SARS-COV-2, vírus esse da espécie da família do coronavírus, é provavelmente uma mutação de um vírus corona existente em morcegos encontrados na província de Hubei, na China1. Esse novo agente foi descoberto em 31/12/2019 e provoca a doença chamada de COVID-19, a qual pode causar no ser humano desde sintomas leves até complicações graves 2 .

Por ser um RNA vírus e da linhagem C do Betacoronavírus, o SARS-COV-2 facilita e determina que ocorra uma maior tendência de mutações e disseminaçōes. Além disso, os coronavírus formam uma grande família de RNA vírus, e são intitulados assim devido à presença de espículas em sua superfície3 . A transmissão ocorre de uma pessoa infectada para outra ou por contato próximo, através de gotículas ou aerossóis salivares, por contato direto ou com objetos ou superfícies contaminadas 4,5 .

O primeiro registro do uso da telemedicina é de 1906, com a consulta eletrocardiográfica remota por telefone. Em 1959, ocorreram as primeiras transmissões de raios- $\mathrm{X}$ e outras imagens entre profissionais, no entanto, a telemedicina teve sua prática verdadeiramente iniciada na década de 1960, nos Estados Unidos, fazendo uso de sistemas de comunicação com o objetivo de monitorar os parâmetros vitais dos astronautas no espaço, a fim de garantir assistência médica da forma mais eficaz possível6.

Um estudo avaliou uma série de artigos sobre a telemedicina, com o intuito de listar as principais vantagens e desvantagens dessa prática. $\mathrm{O}$ desempenho da telemedicina foi analisado em diferentes cenários, com indivíduos do sexo masculino e feminino, de jovens a idosos, e com diferentes condições econômicas e de saúde. Embora algumas barreiras dessa prática foram elencadas, como, a velocidade da internet e a disponibilidade de dispositivos para a consulta, o estudo concluiu que a telemedicina é um formato de atendimento que possui diversos benefícios e uma série de facilitadores7.

$\mathrm{O}$ governo nacional criou, em seis de fevereiro, a lei $n^{\circ} 13.979$, que dispõe sobre as medidas para enfrentamento da Emergência em Saúde Pública de importância Nacional decorrente do coronavírus. Logo, em 15 de março de 2020, foi criada a Lei ${ }^{\circ}$ 13.989 que autoriza o uso da telemedicina enquanto durar a crise ocasionada pelo coronavírus (SARS-CoV-2) 8,9,10.

Antes da chegada da pandemia, causada pelo coranavírus, a telessaúde já vinha sendo muito adotada para levar cuidados especializados à casa de indivíduos doentes e suas famílias. Ela possibilita fornecer acesso rápido a especialistas que não estão imediatamente disponíveis, e isto pode ser ainda de maior valor em países onde certas especialidades são particularmente escassas, sobretudo fora dos grandes centros 7 .

A telemedicina é uma área de assistência médica que se encontra em constante expansão no mundo todo e nada mais é do que a atuação da medicina por meio de tecnologias6. A teleconsulta, também chamada de telessaúde ou consulta remota, 
abrange a interação entre um clínico e um paciente e tem como propósito oferecer aconselhamento diagnóstico ou terapêutico. A consulta remota é uma maneira segura, útil e eficiente de identificar casos suspeitos, orientando o diagnóstico e o tratamento do paciente10. Diferentes relatos apresentados em um estudo comprovam que o uso da telessaúde pode trazer benefícios, como a redução de tempo de atendimento, dos custos de deslocamento de pacientes e profissionais de saúde e melhorias na qualidade assistencial, ao possibilitar o acesso a especialistas por profissionais de saúde não especializados de áreas remota. Um mercado amplo e a flexibilidade das tecnologias digitais atualmente, ajustando-se às necessidades em saúde e na individualidade de cada contexto social, são capazes de proporcionar soluções inovadoras de prestação de serviços de saúde e orientações, abrindo oportunidades para o seu uso no caso das epidemias, mormente a da COVID-19 vivenciada neste momento11 .

O setor saúde vem se reorganizando para absorver o aumento significativo de cuidados em saúde que os infectados necessitam, em especial, os casos moderados e graves. Entretanto, é frequente a notícia de que os serviços oferecidos estão aquém da demanda, e faltam médicos, enfermeiros e equipamentos de proteção individual, entre outros itens fundamentais. É nesse contexto, que o Sindicato dos Trabalhadores das Indústrias de Carnes e Derivados, Frangos, Rações Balanceadas, Alimentação e Afins de Criciúma e Região (SINTIACR), em parceria com a Universidade do Extremo Sul Catarinense (UNESC), organizaram um serviço de suporte ao trabalhador de dois frigoríficos de sua base.

A assistência médica e as empresas de fabricação alimentícia foram consideradas serviços essenciais. Devido a isso, não estão sujeitos ao isolamento social, devendo manter suas atividades para atendimento das necessidades da população. Por sua vez, muitos trabalhadores de dois frigoríficos grandes da base de atuação do SINTIACR procuraram o sindicato para informar que estavam muito receosos de seguir trabalhando. Esses trabalhadores alegaram labo- rar lado a lado com companheiros que apresentavam sintomas gripais, mas que não tinham acesso a serviço de saúde que tivesse capacidade de avaliar e tomar as providências que se fizessem necessárias. Exemplo disso, a emissão de documento para afastamento do trabalho com a finalidade de isolamento social. Ao mesmo tempo, o Ministério da Saúde realizou ação e vanguarda, e editou portaria $n^{\circ} 467$, de 20 de março de 2020, que permitiu o atendimento médico remoto12,13.

A partir disso, o SINTIACR e o Núcleo de Promoção e Atenção Clínica à Saúde do Trabalhador (NUPAC-ST), vinculados à Universidade do Extremo Sul Catarinense (UNESC), organizaram um serviço de teleatendimento médico permitindo o acesso aos trabalhadores, eventualmente desassistidos dos dois frigoríficos citados. Com isso, o objetivo deste relato de experiência é avaliar a experiência do uso de nova estratégia da telemedicina como mecanismo alternativo para prestação da assistência à saúde de casos suspeitos durante a pandemia de COVID-19.

\section{MÉTODOS}

Esta pesquisa se baseou na análise de prontuário médico referente aos atendimentos oferecidos pelo Sindicato aos trabalhadores de dois frigoríficos, um com total de 1.350 trabalhadores, localizado na cidade de Forquilhinha e outro com 2.100 trabalhadores localizados na cidade de Nova Veneza, municípios do interior do estado de Santa Catarina. Este estudo foi caracterizado como epidemiológico observacional descritivo.

O estudo conta com um relato de experiência profissional, que analisou dados referentes ao mês abril de 2020, com um total de 38 atendimentos. Foram analisadas as seguintes variáveis: Sexo, idade, empresa, setor de trabalho, função ocupada, queixa principal, pesquisa clínica de sintomáticos respiratórios, diagnóstico e consulta.

Para o tratamento estatístico e análise epidemiológica, os dados foram analisados através do programa EPI INFO versão 7.

A porta de entrada do serviço se deu a partir do SINTIACR, que divulgou entre trabalhadores dos dois frigoríficos a oferta de atendimento médico por telemedicina para trabalhadores com sintomas gripais. Essa divulgação foi realizada através dos diretores sindicais que trabalham nas duas fábricas.

Ao buscar informações sobre esse serviço junto ao sindicato, o trabalhador era informado que havia uma agenda médica disponível dois dias por semana (segunda e sexta) a partir das 14 horas, com alteração da agenda conforme disponibilidade médica e feriados nacionais, mantendo sempre dois dias semanais.

As consultas foram agendadas conforme contato dos trabalhadores com o sindicato, após, o colaborador comparecia ao local indicado, sendo recebido por um profissional fisioterapeuta ligado a UNESC, devidamente paramentado para contato com paciente potencialmente contaminado por coronavírus. Após alguns esclarecimentos iniciais sobre o serviço, foi explicado aos trabalhadores que se tratava de consulta virtual, e como proceder na situação da teleconsulta. Após a orientação, o fisioterapeuta iniciava um questionário que incluía desde identificação básica até dados relacionados a sintomas respiratórios, os dados do questionário foram previamente estabelecidos em conjunto com o médico responsável, após finalizado o preenchimento os dados eram enviados ao médico por via eletrônica. O local utilizado para as consultas pertencia ao sindicato da categoria e apresentava-se bastante ventilado e com espaço reservado para as consultas. Os equipamentos utilizados foram um computador/notebook, um smartphone, uma impressora para os documentos gerados, um oxímetro de pulso e um termômetro infravermelho digital.

Ao final da consulta, o paciente recebia as orientações devidas, os documentos resultantes do atendimento, como atestado médico para isolamento social, pedido de exames, receita médica para medicações e orientações gerais. Todos esses documentos continham assinatura eletrônica do médico responsável (Com exceção das orientações gerais), os mesmos eram enviados em for- 


\section{artigo}

Matias, M. L., Ruiz, R. C., Justo, T. S., Ribeiro, V. L., Longen, W. C.

A teleconsulta e o alcance da assistência na lógica clínica epidemiológica: um relato de experiência

mato PDF ao fisioterapeuta, que imprimia os documentos repassando-os ao avaliado.

\section{RESULTADOS}

Foram analisados prontuários médico referentes ao atendimento de 38 trabalhadores, na faixa etária de 19 a 50 anos e verificou-se que a maioria era constituída de mulheres. A cidade com o maior número de funcionários foi Forquilhinha seguida por Criciúma. Com relação à empresa de origem, verificou-se que 24 (63,2\%) trabalhadores atuavam na empresa Seara, enquanto 14 (36,8\%) eram da empresa Agrovêneto JBS. Já as funções exercidas se configuram na sua maioria como auxiliar de produção (Tabela 1).

Obteve-se um total de 38 colaboradores que procuraram o serviço de teleatendimento por conta de queixas respiratórias. O critério de atendimento médico se deu a partir da pesquisa de queixa de sintomas respiratórios12,13 que se baseou na busca dos seguintes sinais e sintomas, pesquisados junto aos pacientes: Falta de ar, febre, tosse, disfonia ou rouquidão, dor de garganta, congestão nasal ou coriza, e alteração do paladar e/ou olfato.

Dentre os funcionários que procuraram o teleatendimento, $5(13,2 \%)$ deles apresentavam comorbidades. Asma foi a patologia mais citada pelos trabalhadores acometendo 3 (7,9\%) deles, seguido de $\mathrm{Hi}$ pertensão Arterial Sistêmica (HAS) em 2 $(5,3 \%)$ colaboradores.

Dentre os pacientes que buscaram teleatendimento, não houve correlação entre o setor de atuação dos funcionários do frigorífico com o sintoma dispneia, sendo valor de $p=0,221$. A única correlação estatisticamente significativa encontrada neste estudo foi entre as variáveis dispnéia e suspeita para Covid-19 positiva com valor de $\mathrm{p}=0,037$.

\section{DISCUSSÃO}

Dentre os trabalhadores com sintomas respiratórios que procuraram o serviço de teleatendimento, o principal sintoma relatado pelos pacientes foi tosse, juntamente de congestão nasal ocorrendo na mesma
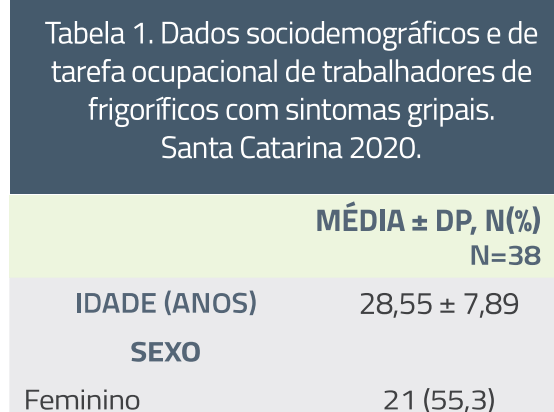

MÉDIA \pm DP, N(\%) $\mathrm{N}=38$ $28,55 \pm 7,89$

Feminino $21(55,3)$

Masculino $17(44,7)$

CIDADE

Forquilhinha

$29(76,3)$

Criciúma $6(15,8)$

Araranguá

$2(5,3)$

Nova Veneza

\section{EMPRESA}

Seara

$24(63,2)$

Agrovêneto

$14(36,8)$

SETOR

Corte da coxa

$14(36,8)$

Corte do peito

$5(13,2)$

Corte da perna

$5(13,2)$

Corte da asa

$4(10,5)$

Refile do peito

$3(7,9)$

SIF

$2(5,3)$

Expedição

$2(5,3)$

Congelamento

$1(2,6)$

Miúdos

$1(2,6)$

Mercado interno

$1(2,6)$

Legenda: Número real (n) ou porcentagem relativa $(\%)$ das seguintes variáveis: Idade, sexo, cidade, empresa, setor Fonte: Dados da pesquisa, 2020.

frequência (Tabela 2). Em um estudo 14, o sintoma mais relatado entre os pacientes com COVID foi tosse (67,8\%), seguido de congestão nasal (4,8\%).

Dentre os funcionários que procuraram o teleatendimento, 5 apresentavam comor-
Tabela 2. Sintomas gripais nos trabalhadores de frigoríficos atendidos em teleconsulta.

\begin{tabular}{lc}
\multicolumn{1}{c}{ SINTOMAS } & \multicolumn{1}{c}{$\mathbf{N ( \% )}$} \\
& $\mathbf{N}=38$ \\
Tosse & $27(71,1)$ \\
Congestão Nasal & $27(71,1)$ \\
Dor de garganta & $26(68,4)$ \\
Disfonia / Rouquidão & $23(60,5)$ \\
Febre & $18(47,4)$ \\
Dispnéia & $15(39,5)$ \\
Alteração de paladar & $15(39,5)$ \\
e/ou olfato & \\
Cefaléia & $5(13,2)$ \\
Legenda: Número real (n) ou porcentagem relativa (\%) das \\
varíuveis relacionadas anintomas gripais. \\
Fonte: Dados da pesquisa, 2020.
\end{tabular}

Tabela 3. Fatores de risco e suspeita de Covid-19 nos trabalhadores de frigorificos atendidos em teleconsulta.

$N(\%)$

$\mathrm{N}=38$

$\begin{array}{ll}\text { Fator de risco } & 5(13,2) \\ \text { Asma } & 3(7,9) \\ \text { HAS } & 2(5,3)\end{array}$

Suspeita COVID-19 $32(84,2)$

Legenda: Número real (n) ou porcentagem relativa $(\%)$ das variáveis comorbidades e suspeita Covid-19.

Fonte: Dados da pesquisa, 2020

bidades (Tabela 3). Em pesquisa de Guan et al. (2020)15, foi observado que $23.7 \%$ possuíam ao menos uma doença coexistente, Hipertensão Arterial Sistêmica atingiu 15,0\% deles. O artigo de Onder et al. (2020) 16 concluiu que fatores de risco podem favorecer o desenvolvimento das for-

Tabela 4. Correlação entre idade e dispnéia nos trabalhadores de frigoríficos atendidos em teleconsulta.

\begin{tabular}{|c|c|c|c|}
\hline \multicolumn{4}{|c|}{ DISPNEIA, N(\%),MÉDIA \pm DP } \\
\hline \multirow[b]{3}{*}{ Idade (anos) } & $\operatorname{Sim}$ & Não & Valor-p \\
\hline & $n=15(39,5)$ & $n=23(60,1)$ & \\
\hline & $27,87 \pm 6,22$ & $29,00 \pm 8,92$ & 0,976 \\
\hline
\end{tabular}


Tabela 5. Relação entre as variáveis dispnéia vs setor e dispnéia vs suspeita Covid-19 nos trabalhadores de frigorificos atendidos em teleconsulta.

\begin{tabular}{|c|c|c|c|}
\hline & \multicolumn{2}{|c|}{ COVID-19, N (\%) } & \multirow{3}{*}{ Valor-p } \\
\hline & $\begin{array}{l}\text { Suspeita Po- } \\
\text { sitiva }\end{array}$ & $\begin{array}{l}\text { Suspeita Ne- } \\
\text { gativa }\end{array}$ & \\
\hline & $n=32$ & $n=6$ & \\
\hline \multicolumn{4}{|l|}{ SETOR } \\
\hline Corte da coxa & $11(34,4)$ & $3(50,0)$ & \multirow[t]{10}{*}{$0,221 \dagger$} \\
\hline Corte do peito & $3(9,4)$ & $2(33,3)$ & \\
\hline Corte da perna & $5(15,6)$ & $0(0,0)$ & \\
\hline Corte da asa & $4(12,5)$ & $0(0,0)$ & \\
\hline Refile do peito & $3(9,4)$ & $0(0,0)$ & \\
\hline \multirow[b]{2}{*}{ Expedição } & $2(6,3)$ & $0(0,0)$ & \\
\hline & $2(6,3)$ & $0(0,0)$ & \\
\hline \multirow{2}{*}{$\begin{array}{l}\text { Congelamento } \\
\text { Miúdos }\end{array}$} & $1(3,1)$ & $0(0,0)$ & \\
\hline & $0(0,0)$ & $1(16,7)$ & \\
\hline MERCADO INTERNO & $1(3,1)$ & $0(0,0)$ & \\
\hline \multicolumn{4}{|l|}{ DISPNEIA } \\
\hline $\operatorname{Sim}$ & $15(46,9) b$ & $0(0,0)$ & $0,037 \neq$ \\
\hline Não & $17(53,1)$ & $6(100,0) b$ & \\
\hline \multicolumn{4}{|c|}{$\begin{array}{l}\text { Legenda: Número real (n) ou porcentagem relativa (\%) e Correlação entre setor vs. Suspeita Covid-19 e dispnéia vs. suspeita Covid-19. } \\
\text { tValor obtido após aplicação do teste razão de verossimilhança. } \\
\text { tValor obtido após aplicaçã o do teste Exato de Fisher. bLetra indicando valor estatisticamente significativo após análise de resíduo. } \\
\text { Fonte: Dados da pesquisa, 2020. }\end{array}$} \\
\hline
\end{tabular}

mas mais graves de COVID-19Os aspectos mais significativos são a idade avançada e a presença de comorbidades. As patologias mais encontradas em seu estudo foram as respiratórias crônicas, doenças cardíacas, doenças renais, diabetes e hipertensão. No estudo de Chen et al. (2020)17, foi observado que $63 \%$ dos casos que foram a óbito e $39 \%$ dos que se recuperaram tinham, pelo menos, uma doença crônica. $\mathrm{O}$ ambiente dos frigoríficos proporciona aglomeração de funcionários que trabalham nas linhas de produção.

O ambiente dos frigoríficos proporciona aglomeração de funcionários que trabalham nas linhas de produção. Além disso, as condições ambientais apresentam como características as baixas temperaturas e restrição da renovação do ar. Isso favorece a disseminação do vírus e leva a uma alta taxa de contágio nesses ambientes. Outro fator agravante para aumento de contaminação ocorre pela migração pendular diária de trabalhadores entre municípios vizinhos em transportes coletivos, o que pode proporcionar o surgimento e o aumento no número de casos não apenas na cidade sede dos frigoríficos 18. Segundo um estudo, ações de vigilância e educação em saúde de trabalhadores são importantes para identificar problemas e fatores de risco, bem como articular o conhecimento científico para uma melhor prática assistencial, oportunizando espaços seguros aos trabalhadores no retorno de suas atividades laborais 19.

O último dado analisado nesta pesquisa foi o desfecho em relação ao atendimento médico. Os 38 trabalhadores atendidos receberam atestados médicos para iniciarem ou completarem afastamento inicial de 14 dias, sendo que $100 \%$ dos trabalhadores receberam pedido de exame específico para diagnóstico etiológico, o RT PCR COVID-19. Todos foram orientados a procu- rar o serviço público municipal de saúde para realização dos exames, mas nenhum resultado retornou aos pesquisadores até o momento. Alguns trabalhadores informaram que a resposta do serviço público de saúde foi a não possibilidade de realizar o teste devido à falta de insumos necessários para o mesmo.

Finalmente, destaca-se que ao final de cada dia de atendimento, foi elaborado um ofício à vigilância epidemiológica municipal relatando os atendimentos realizados, com a lista de casos suspeitos descritos nominalmente e com os seus contatos telefônicos respectivos.

\section{CONCLUSÃO}

Embora a teleconsulta apresente alguns fatores limitadores, conclui-se que ela pode ser uma grande aliada na assistência médica, com prestação de consulta e orientações, visto que a mesma conta com diferentes benefícios, já citados nessa pesquisa, principalmente em eventos que a população tem que conviver com isolamento social, como em casos de crises pandêmicas.

Os resultados encontrados e evidenciados nesse estudo demonstram que o uso da telemedicina como uma ferramenta acessória ou de apoio a avaliação em saúde pode se constituir em importante dispositivo no conjunto de práticas assistenciais oferecidas a população, de modo a contribuir com a eficiência do sistema como um todo. 


\section{artigo}

Matias, M. L., Ruiz, R. C., Justo, T. S., Ribeiro, V. L., Longen, W. C.

A teleconsulta e o alcance da assistência na lógica clínica epidemiológica: um relato de experiência

\section{REFERÊNCIAS}

1-Defesa, Ministério da. Crise Covid-19 estratégias de transição para a normalidade: centro de estudos estratégicos, exército brasileiro. Centro de estudos estratégicos, Exército Brasileiro, 2020.

2- Brasil. Ministério da Saúde. Protocolo de Manejo Clínico para o Novo Coronavírus (2019-nCoV). P.32. Brasília, 2020.

3-Duarte G, Quintana SM. Infecção pelo Corona Vírus SARS-COV-2 em obstetrícia.: enfrentando o desconhecido. : Enfrentando o desconhecido. Associação de Obstetrícia e Ginecologia do Estado de São Paulo: SOGESP, São Paulo, v., n., p. 1-10, 02 ago. 2020.

4-Brasil. Ministério da Saúde. Protocolo de Manejo Clínico do Coronavírus (COVID-19) na Atenção Primária à Saúde. P.35, Brasília, 2020

5- Andersen KG, Rambaut A, Lipkin WI, Holmes EC, Garry RF. The proximal originof SARS-CoV-2. Nature Medicine, [s.I.], p. 1-5, 02 ago. 2020. Springer Science and Business Media LLC. http://dx.doi. org/10.1038/s41591-020-0820-9.

6- BInda Filho DL. TELEMEDICINA EM TEMPOS DE PANDEMIA: SERVIÇOS REMOTOS DE ATENÇÃO À SAÚDE NO CONTEXTO DA COVID-19. 2020.

7-Almathami, HK ; Win, KT. Barriers and Facilitators That Influence Telemedicine-Based, Real-Time, Online Consultation at Patients' Homes: Systematic literature review. Journal Of Medical Internet Research, [S.L.], v. 22, n. 2, p. 16407-16418, 20 fev. 2020. JMIR Publications Inc.. http://dx.doi.org/10.2196/16407.

8-Brasil. Decreto No 10.282, de 21 de março de 2020. Regulamenta a Lei $n^{\circ} 13.979$, de 6 de fevereiro de 2020, para definir os serviços públicos e as atividades essenciais. Diário Oficial Da União: seção 1, p. 1. Brasília, DF,21 mar. 2020a.

9- Brasil. Lei n 13.979, de 06 de fevereiro de 2020. Dispõe sobre as medidas para enfrentamento da emergência de saúde pública de importância internacional decorrente do coronavírus responsável pelo surto de 2019. Diário Oficial da União: seção 1, p. 1. Brasília,DF, 06 mar. 2020b.

10-Brasil. Lei $n^{\circ}$ 13.989, de 15 de abril de 2020. Dispõe sobre o uso da telemedicina durante a crise causada pelo coronavírus (SARS-CoV-2). Diário Oficial da União: seção 1, Brasília, DF, p.1, 16 abr. 2020 c

11-Caetano, R; Silva, AB. Desafios e oportunidades para teles saúde em tempos da pandemia pela COVID-19: uma reflexão sobre os espaços e iniciativas no contexto brasileiro. Cadernos de Saúde Pública, [S.L.], v. 36, n. 5, p. 345-356, 2020. FapUNIFESP

\section{(SciELO). http://dx.doi.org/10.1590/0102-311x00088920.}

12-Opas. Organização Pan-Americana da Saúde. Teleconsulta durante uma pandemia: Departamento de Evidência e Inteligência para Ação e Saúde. Brasília (DF); 2020.

13-Santa Catarina. Decreto $n^{\circ}$ 515, de 17 de março de 2020. Declara situação de emergência em todo o território catarinense, nos termos de COBRADE No 1.5.1.1.0 - Doenças infecciosas virais, para fins de prevenção e enfrentamento à COVID-19, e estabelece outras providências. Diário Oficial do Estado de Santa Catarina, Florianópolis, 17 mar. 2020. p.11.

14-Brasil. Ministério da Saúde. Guia de Vigilância Epidemiológica: Emergência de Saúde Pública de Importância Nacional pela Doença pelo Coronavírus 2019. Brasília, DF, 2020d.

15-Guan W et al. Clinical Characteristics of Coronavirus Disease 2019 in China. New England Journal Of Medicine, [S.L.], v. 382, n. 18, p. 1708-1720, 30 abr. 2020. Massachusetts Medical Society. http://dx.doi.org/10.1056/nejmoa2002032.

16-Onder G, Rezza G, Brusaferro S. Case-Fatality Rate and Characteristics of Patients Dying in Relation to COVID-19 in Italy. Jama, [S.L.], p. 1775-1776, 23 mar. 2020. American Medical Association (AMA). http://dx.doi.org/10.1001/jama.2020.4683.

17- Chen T et al. Clinical characteristics of 113 deceased patients with coronavirus disease 2019: retrospective study. Bmj, [S.L.], p. 1-12, 26 mar. 2020. BMJ. http://dx.doi.org/10.1136/bmj.m1091.

18-Heck FM et al. Os territórios da degradação do trabalho na Região Sul e o arranjo organizado a partir da COVID-19. Metodologias e Aprendizado, [S.L.], v. 3, p. 54-68, 20 jun. 2020. Instituto Federal Catarinense. http://dx.doi.org/10.21166/metapre. v3i0.1332.

19-Oliveira, ACS; Silva, GF. Atenção à saúde do trabalhador na vigilância ao COVID-19: um relato de experiência. Saúde Coletiva (Barueri), [S.L.], v. 11, n. 60, p. 4600-4609, 5 jan. 2021. MPM Comunicacao. http://dx.doi.org/10.36489/saudecoletiva.2021v11i60p4600-4609. 